\section{CONGENITAL CORONARY ARTERIOVENOUS FISTULA}

BY

\section{J. L. BRAUDO, M.D., M.R.C.P.Ed.}

S. N. JAVETT, M.D., D.C.H.

M. M. ZION, M.D., M.R.C.P.

AND

\section{I. ADLER, F.R.C.S.Ed。 \\ Johannesburg, South Africa}

Congenital coronary arteriovenous fistula is an uncommon anomaly. Steinberg et al. (1958) reviewed 21 cases and added one of their own. The majority of the patients were asymptomatic. However, three deaths due to cardiac failure consequent upon the fistula were recorded. Gasul et al. (1960) reported five cases, four of which were successfully operated upon. The diagnosis was suspected and proved pre-operatively in three of the five. Fourteen other fistulae have been closed satisfactorily (Gasul et al., 1960 ; Lam et al., 1960 ; Amplatz et al., 1960). This paper describes the case of a symptomatic 4-year-old white girl in whom the diagnosis was suspected clinically and proved by cardiac' catheterization and retrograde aortography. The abnormal left circumflex coronary artery was surgically ligated and she has been completely asymptomatic since her operation two and a half years ago.

\section{Case Report}

A $3 \frac{1}{2}$-year-old white girl was first seen on November 13 , 1957, for assessment of a heart murmur, which had been noted one month previously during a bout of influenza. After this latter illness, breathlessness on exertion became evident for the first time. Her past history and family history were non-contributory.

Physical examination revealed a small, fairly well nourished child-weight $13.5 \mathrm{~kg}$. (10th percentile) and height $94 \mathrm{~cm}$. (10th percentile). Cyanosis and-clubbing were not evident. There were no signs of congestive cardiac failure. The pulse was collapsing in quality and the blood-pressure in the right arm measured $80 / 30 \mathrm{~mm}$. $\mathrm{Hg}$ and in the right leg $124 / 40 \mathrm{~mm}$. Hg. The heart was not clinically enlarged. It was overactive and a left ventricular apical impulse was noted. A systolic thrill was felt in the xiphisternal region and along both sides of the lower end of the sternum. The first heart sound was normal. The second heart sound was well split and moved normally on respiration, with both components of equal intensity. A continuous murmur grade $4 / 6$ with systolic accentuation was audible in the tricuspid area. It radiated to the xiphisternum and lower left sternal border. At the apex a mid-diastolic murmur grade 1-2/4 was noted. The remainder of the clinical examination was essentially negative.

Her electrocardiogram showed an $r R^{\prime}$ pattern in 4VR and $\mathrm{rSr}^{\prime}$ in $\mathrm{Vi}$. $X$-ray examination of the heart revealed a cardiothoracic ratio of $45 \%$. No chamber enlargement was demonstrated, but the pulsation in the right atrium, pulmonary artery, and aorta was excessive. The lung vascularity was within normal limits.

Phonocardiography confirmed the continuous murmur (Fig. 1). The duration of the second sound was 0.05 second. The differential diagnosis at this stage was: (1) coronaryartery/coronary-vein fistula, (2) coronary-artery/right-atrium fistula, (3) arteriovenous malformation of right internal mammary vessels, or (4) rupture of a sinus of Valsalva into the right atrium. Cardiac catheterization performed on November 21 revealed a left-to-right shunt of $4.71 . / \mathrm{min} . / \mathrm{m}^{2}$ at atrial level (see Table below). All pressures on the right . side of the heart were normal. Axillary artery pressure was $77 / 22 \mathrm{~mm}$. Hg. A retrograde aortogram utilizing the femoral artery was unsuccessful. She returned to her home in Rhodesia and was seen again in November, 1958.

In the intervening year her cardiac status had deteriorated. Her dyspnoea had become more severe and attacks of paroxysmal nocturnal dyspnoea had appeared. Sweating in winter and periorbital oedema had been observed. Physical examination now revealed a pale, dyspnoeic child. Apart from the development of periorbital oedema there were no significant changes in the physical findings. Her weight was $15 \mathrm{~kg}$. (10th-25th percentile) and height $100 \mathrm{~cm}$. (25th percentile). The electrocardiogram showed two changes-the $P$ wave in standard leac II was taller (Fig. 2) and the duration of electrical systole in V1 had increased from 0.06 to 0.075 second. $X$-ray examination showed an increase in heart size, with a very prominent right atrial shadow (Fig. 3). Retrograde aortography utilizing the right axillary artery demonstrated an abnormally wide left coronary artery and a small aortic root (Fig. 4). The diagnosis of a coronaryartery/coronary-vein or coronary-artery/right-atrium fistula was therefore confirmed. She was referred to Mr. D. Adler, who on November 28 ligated the abnormal left circumflex coronary artery in two places.

At operation the right coronary artery appeared normal. The left coronary artery was markedly dilated except for the anterior ascending branch. It was felt that the circumflex branch, which was very hypertrophied and felt like a lead pencil, was the cause of the fistula. Presstre on this branch of the coronary artery at its insertion into the right atrium caused the thrill to disappear. Isolation of the coronary

\begin{tabular}{|c|c|c|c|c|c|c|}
\hline & \multicolumn{2}{|c|}{$\begin{array}{c}\text { Blood Oxygen } \\
\text { Content } \\
\text { (Vols. \%) }\end{array}$} & \multicolumn{2}{|c|}{ Pressure (mm. Hg) } & \multicolumn{2}{|c|}{$\underset{\left(1 . / \mathrm{min} . / \mathrm{m} .{ }^{2}\right)}{\text { Flow }}$} \\
\hline & $\begin{array}{l}\text { Pre- } \\
\text { op. }\end{array}$ & $\begin{array}{l}\text { Post- } \\
\text { op. }\end{array}$ & Pre-op. & Post-op. & $\begin{array}{l}\text { Pre- } \\
\text { op. }\end{array}$ & $\begin{array}{l}\text { Post- } \\
\text { op. }\end{array}$ \\
\hline 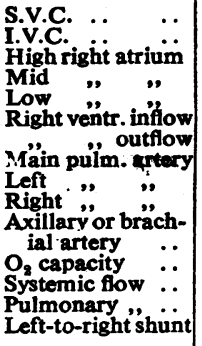 & $\begin{array}{r}9.1 \\
9.9 \\
11.3 \\
11.3 \\
11 \\
11.3 \\
11.2 \\
11.8 \\
11.8 \\
11.2 \\
13.7 \\
14.3\end{array}$ & $\begin{array}{c}10.48 \\
11.4 \\
10.48 \\
11.53 \\
1.1 \\
11.2 \\
10.9 \\
10.97 \\
- \\
14.8 \\
16.3\end{array}$ & $\begin{array}{l}4 / 0 \mathrm{~m} .=2 \\
18 / 0 \\
18 / 0 \\
18 / 8 \cdot \mathrm{m} .=12 \\
72 / 22 \mathrm{~m} .=36\end{array}$ & $\begin{array}{l}3 / 0 \mathrm{~m} .=2 \\
17 / 0 \\
17 / 0 \\
17 / 8 \mathrm{~m} .=12 \\
90 ; 60 \mathrm{~m} .=75\end{array}$ & $\begin{array}{l}4 \cdot 4 \\
9 \cdot 1 \\
4 \cdot 7\end{array}$ & $\begin{array}{l}4 \cdot 7 \\
4 \cdot 7\end{array}$ \\
\hline
\end{tabular}

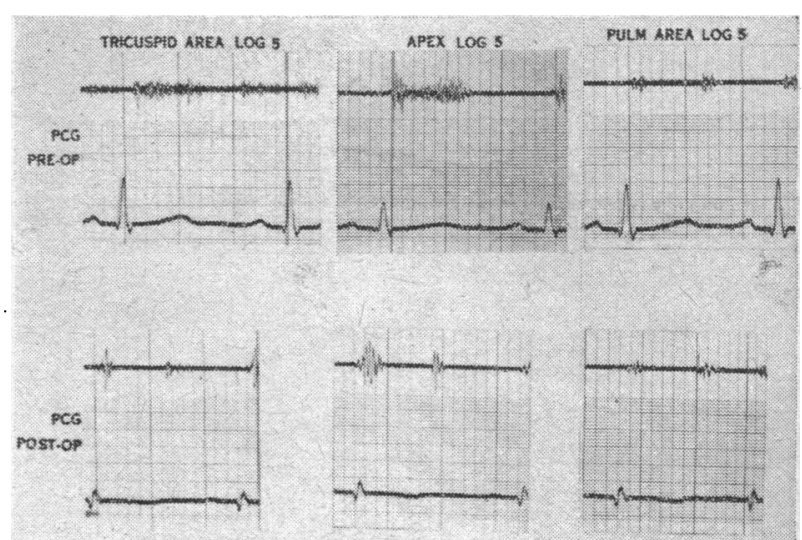

FIG. 1.-Pre-operative phonocardiogram demonstrating continuous murmur in tricuspid area and well-marked splitting of second sound in pulmonary area. Post-operative phonocardiogram shows no continuous murmur and a decrease in duration of second heart sound. 
artery at this site, however, proved to be very difficult, as the coronary sinus was flattened like a tape over it. Although the coronary artery could have been ligated here the ligature would have had to include the coronary sinus. The circumflex branch was therefore ligated high up just after the anterior ascending branch had been given off. An electrocardiogram (standard lead II) showed no change after five minutes' obliteration. The coronary artery was therefore doubly ligated at this site with immediate shrinkage of the size of the heart and disappearance of the thrill in the right atrium which now became quite lax and small.

\section{Progress}

Her post-operative course was clinically uneventful. The post-operative electrocardiogram showed progressive $T$-wave (Fig. 5) changes which could have been produced by coronary ischaemia or traumatic post-operative haemorrhagic pericarditis (Papp and Zion, 1956). Improvement after surgery was dramatic. Her periorbital oedema, sweating, dyspnoea on exertion, and paroxysmal nocturnal dyspnoea disappeared almost immediately. When seen in April, 1960, aged $5 \frac{1}{2}$ years, 18 months after her operation, her weight was $18 \mathrm{~kg}$. (25th percentile) and height $112 \mathrm{~cm}$. (25th percentile). Colour was normal. There were no signs of congestive cardiac

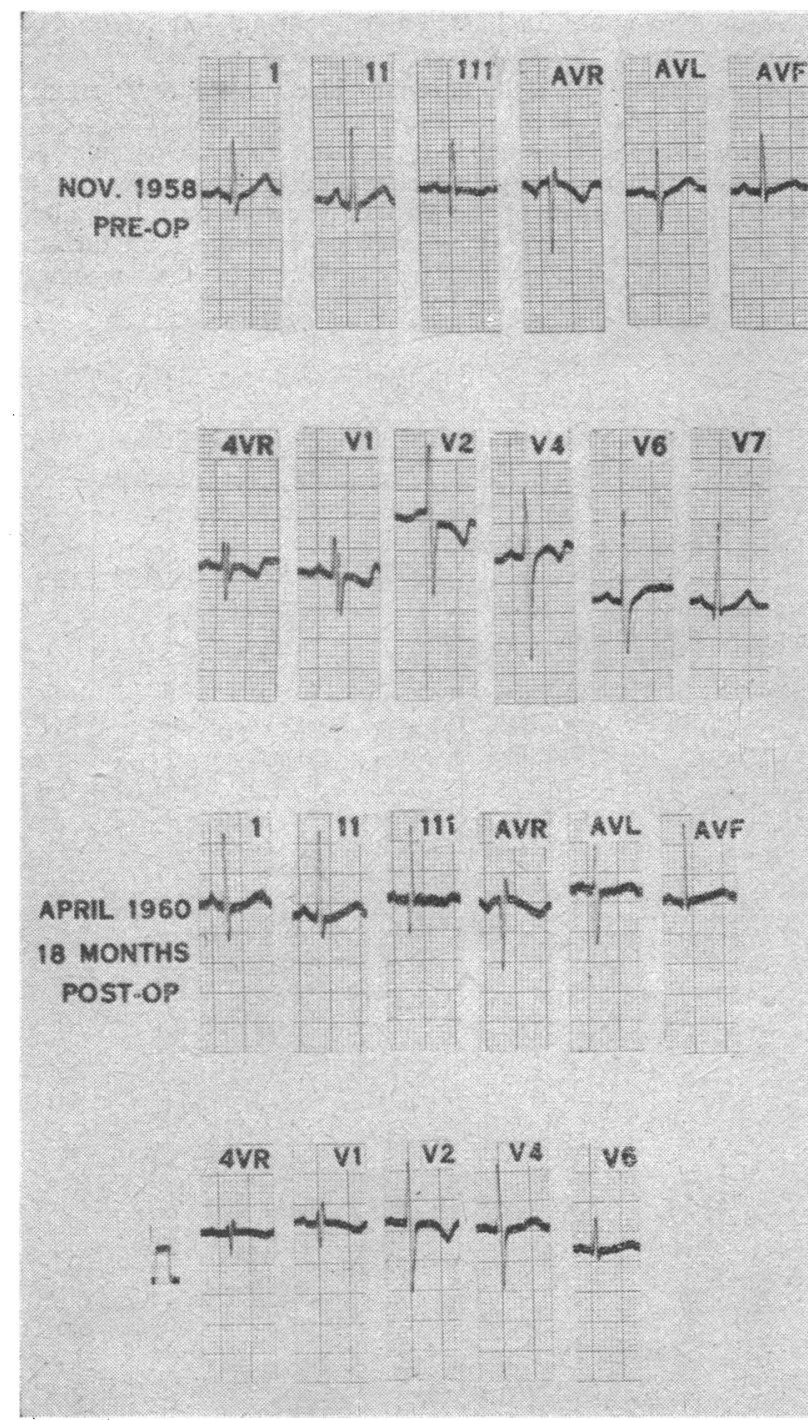

Fio. 2.-Electrocardiogram immediately prior to surgery. The $P$ wave in standard lead II is more prominent and the duration of electrical systole in $\mathrm{V} 1$ and $4 \mathrm{VR}$ has increased from 0.06 to 0.075 second. Electrocardiogram 18 months after surgery shows a normal $P$. wave and a decrease in duration of right ventricular systole. failure. Pulse volume was normal and the blood-pressure in the right arm $90 / 60 \mathrm{~mm}$. Hg. The heart was quiet in its action. No thrill was palpable. The first heart sound was normal. The second heart sound was normally split. An early systolic pulmonary click was heard. There were no murmurs. The electrocardiogram now showed a decrease in duration of QRS in V1-0.05 second and the $P$ wave was smaller (Fig. 2). $X$-ray examination of the heart showed a decrease in size of the right atrium (Fig. 6). Her phonocardiogram was normal (Fig. 1). Cardiac catheterization did not reveal a shunt at atrial level (see Table).

\section{Discussion}

The subject has been thoroughly reviewed by Steinberg et al. (1958). Of the 21 previously reported

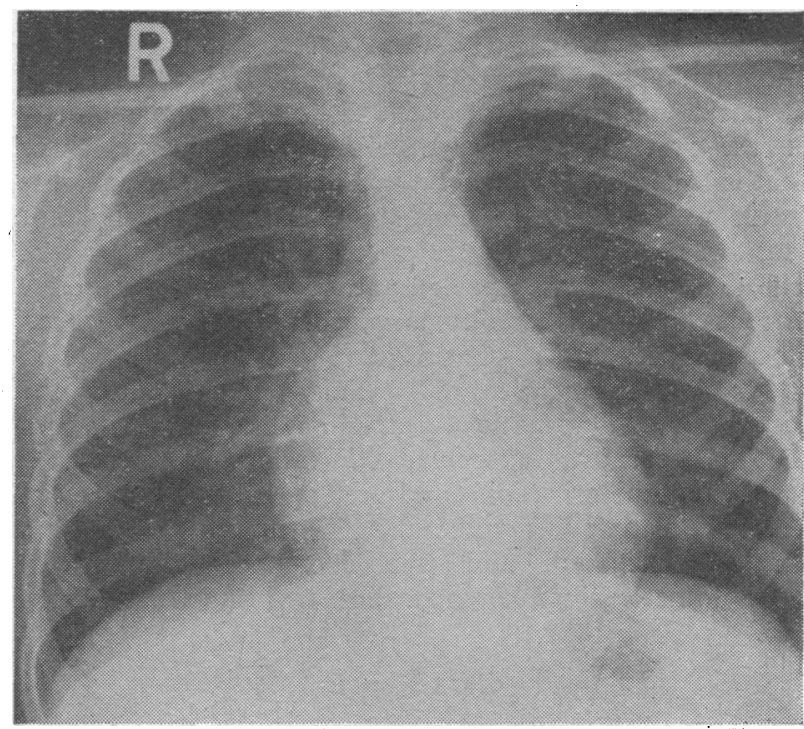

Fig. 3.-Teleradiograph of chest immediately prior to operation shows a definite increase in heart size with enlargement of right atrium.

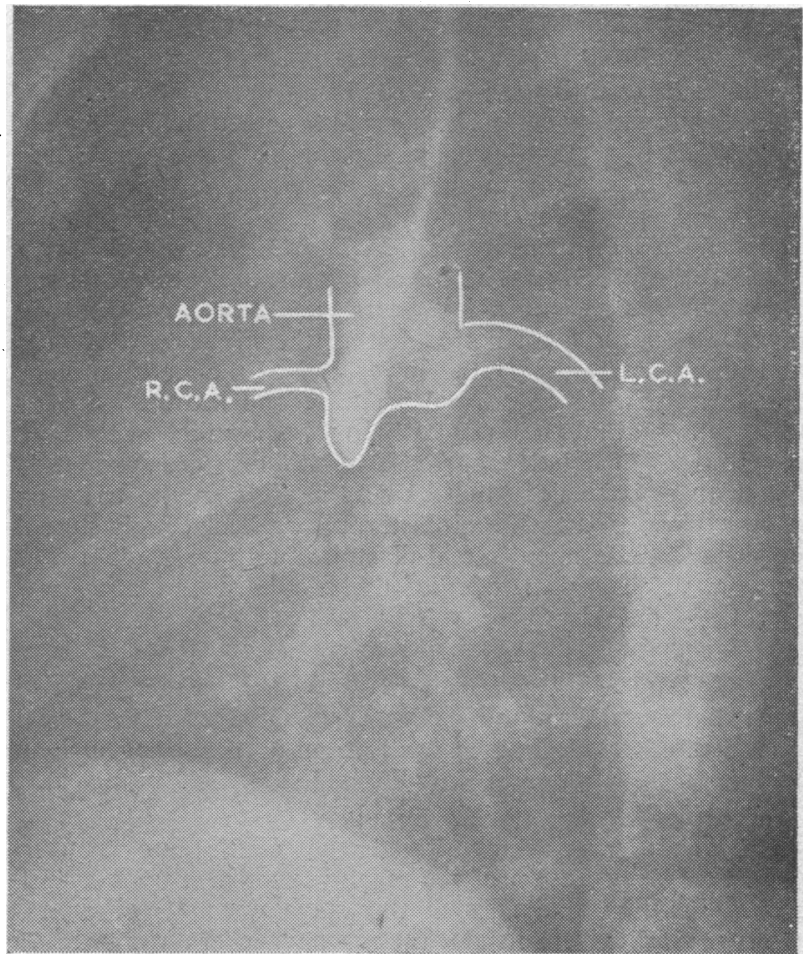

Fig. 4.-Retrograde aortogram outlining dilated left coronary artery and narrow ascending aorta. 
coronary arteriovenous fistulae, 13 were discovered at necropsy. In eight cases the condition was diagnosed during life by thoracotomy (seven cases) or cardiac catheterization (one case).

Gasul et al. (1960) reported five cases in great detail. In three the condition was correctly diagnosed pre-

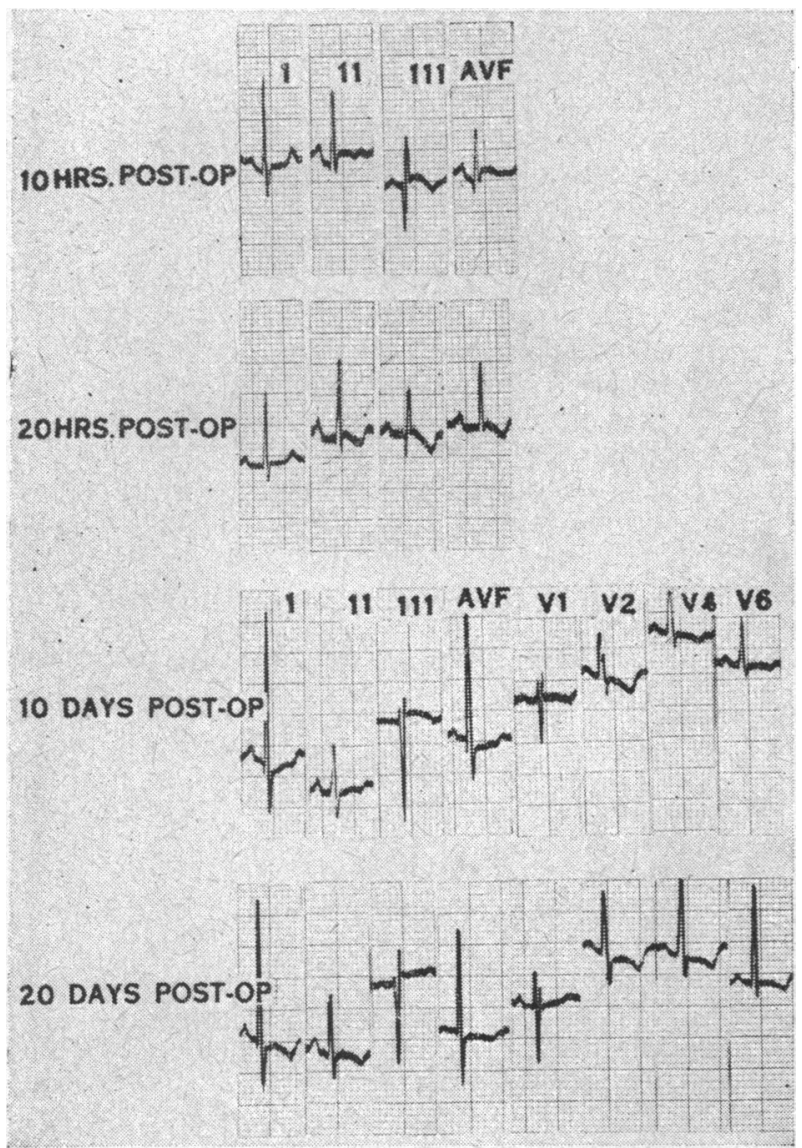

FIG. 5.-Immediate post-operative electrocardiograms with ST and $T$ wave changes compatible with post-pericardiotomy syndrome or ischaemia of myocardium.

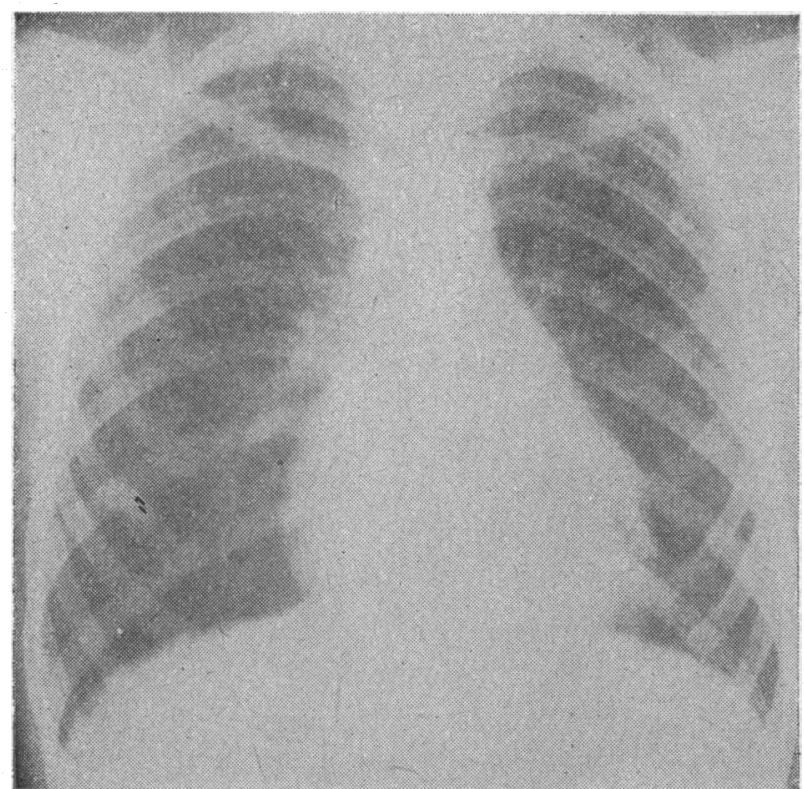

Fig. 6. - Teleradiograph of chest 18 months post-operatively. Note decrease in size of heart and right atrium. operatively by means of cardiac catheterization and angiocardiography, demonstrating the abnormal coronary vessel.

It is important to diagnose and treat these fistulae, since they may impose a great strain on the heart. The presence of a continuous murmur over the praecordium and not in the usual patent ductus site should make one include this type of fistula in the differential diagnosis. The site of maximum intensity of the murmur would depend upon the anatomical region of entry of the abnormal vessel. Analysis of 26 adequately reported cases showed right coronary artery involvement in 14 cases and left in 12 . The fistulous connexion entere the right ventricle in eight patients, a coronary vein in six, the pulmonary artery in five, the right atrium and coronary sinus in three each, and the left atrium in one.

A machinery murmur in the ductal site would be present if the abnormal vessel entered the pulmonary artery or infundibulum of the right ventricle. The commonest sites, however, are the lower portion of the right ventricle, right atrium, and coronary sinus. Under these circumstances the murmur would be present to the right of the sternum in the third and fourth right interspaces. Occasionally, especially in the infant, it may be heard at the apex or medial to it.

Some assistance in diagnosis can be obtained by $x$-ray examination of the heart. The presence of an enlarged right atrium would suggest entry of the coronary vessel into that chamber or the coronary sinus. Lung vascularity is usually normal. The aorta may be prominent. Electrocardiography is usually normal but may show right atrial enlargement, a dilated right ventricle, and even left ventricular hypertrophy.

Cardiac catheterization would depict the site of the left-to-right shunt. If the coronary artery entered the coronary sinus and relatively well oxygenated blood was obtained from this site a confident diagnosis of this condition could be made.

Angiocardiography is the method of choice. Retrograde aortography with the catheter placed just above the aortic valve should permit accurate delineation of the coronary artery involved. With the newer methods for specific visualization of the coronary arteries and their branches it should be possible to. outline the coronary artery involved and its site of entry into the heart. Gasul et al. (1960) diagnosed three cases preoperatively by the abnormal site of the machinery murmur and adequate cardiac catheterization and angiographic studies. The case reported by Steinberg et al. was diagnosed, but surgery was not contemplated as the patient was asymptomatic.

In the 21 cases analysed by Steinberg et al., 13 were proved at necropsy, having been undiagnosed during life. In three of these $\mathbf{1 3}$ death was attributable to their coronary arteriovenous fistulae. The ages of these patients were 25,58 , and 62 years. The condition may therefore be fatal.

In our patient the diagnosis was suspected on clinical grounds and proved by retrograde aortography. It is now two and a half years since the abnormal coronary artery was ligated and she remains asymptomatic.

\section{Summary}

A case of coronary arteriovenous fistula in a symptomatic 4-year-old girl is described. 
The condition was suspected clinically and diagnosed pre-operatively by cardiac catheterization and retrograde angiocardiography.

The abnormally large left circumflex coronary artery entered the coronary sinus.

Surgical ligation of the coronary artery has resulted in noticeable improvement in the patient's cardiovascular status.

\section{REFERENCES}

Amplatz, K., Aguirre, J., and Lillehei, C. W. (1960). J. Amer. med. Ass., 172, 1384

Gasul, B. M., Arcilla, R. A., Fell, E. H., Lynsfield, J., Bicoff, J. P., and Luan, L. L. (1960). Pediatrics, 25, 531 .

Lam, C. R., Dammann, J. F., jun., Dotter, C. T., O'Loughlin, B. J., Cooley, D. A., and Julian, O. C. (1960). Arch. Surg. (Chicago), 80, 518 (Case 4).

Papp, C., and Zion, M. M. (1956). Brit. Heart J., 18, 153

Steinberg, 1., Baldwin, J. S., and Dotter, C. T. (1958). Circulation, 17, 372 .

\section{METHYLPREDNISOLONE ACETATE IN INTRA-ARTICULAR THERAPY CLINICAL, BIOCHEMICAL, AND CHROMATOGRAPHIC STUDIES}

BY

\section{W. R. MURDOCH, M.B., F.R.F.P.S., M.R.C.P. M.R.C.P.Ed.}

Senior Medical Registrar, Dumfries and Galloway Royal Infirmary

AND

G. WILL, M.B., B.Sc., F.R.F.P.S.

Senior Medical Registrar, Glasgow Royal Infirmary

In rheumatoid arthritis the local and general symptoms are often adequately controlled by physiotherapy combined with analgesics or oral steroids. Yet in some patients, while there is general improvement with this treatment, acute symptoms persist in one or more joints. This is particularly so in the weight-bearing foints, where pain and effusion may severely limit mobility. In such cases intra-articular therapy would appear to have much to commend it, as it should be possible to ensure a high local concentration of steroid while avoiding the sideeffects of systemic administration.

In recent years a number of synthetic steroids of greater potency than the original compounds-cortisone and hydrocortisone-have been produced. Some of these compounds are suitable for intra-articular injection. We report here our experience with the intra-articular administration of a new steroid, methylprednisolone acetate.

\section{The Investigation}

As in our previous work (Murdoch and Will, 1959a), knee-joints were used, their size and ease of access making it possible to obtain serial specimens of joint fluid. Joint effusion was tabulated into four grades: marked $(+++)$; moderate $(++)$; slight, where there was patellar tap only $(+)$; and no effusion. Pain was assessed in four grades: severe $(+++)$; moderate $(++)$, mild $(+)$, and absent. The cytological and biochemical changes of the joint fluid were studied, and an assessment was made of the persistence of the steroid within the joint cavity. During the trial a standard dose of $40 \mathrm{mg}$. of methylprednisolone acetate in $1 \mathrm{ml}$. was injected at weekly intervals until complete relief of pain and swelling was obtained.
Aspirations were carried out in 69 joints. The total number of rheumatoid patients was 48 . Twenty-six patients were admitted to the wards for the initial period of treatment and were subsequently seen at regular intervals as out-patients. During the period of investigation the patients received no treatment other than simple analgesics.

The knee-joints were entered from the lateral aspect at the level of the upper border of the patella with the limb in extension. Only a small volume of fluid (3-5 ml.) sufficient to permit routine analysis was removed. The number of injections given per joint varied from one to six, with an average of 2.8 . The period of follow-up ranged from 10 to 30 months, with an average of 18 months.

In six patients with bilateral effusions of comparable severity one knee was used initially as a control, being given an injection of $1 \mathrm{ml}$. of lignocaine, while the other knee received the standard dose of methylprednisolone acetate. Thereafter both knees were given the steroid. In contradistinction to the treated knees, the control knees showed no improvement in pain and swelling. The cell count rose in every case, and there was no significant alteration in the protein content. As these results corresponded closely with our previous experience (Murdoch and Will, 1959a, 1959b) the control group was not extended further.

\section{Clinical Results}

The initial status of the joints with regard to pain and effusion is shown in Table $I$. The usual response to injection was relief of pain beginning within six hours and becoming complete within 24 hours. In more than half the patients only two injections were required to produce resolution of the effusion. Where effusions were bilateral the two joints always responded similarly to treatment. Fig. 1 records the number of injections required to produce relief of pain and resolution of

\begin{tabular}{|c|c|c|c|c|c|}
\hline & Grade: & $+t+$ & $+:$ & + & 0 \\
\hline $\begin{array}{l}\text { Effusion } \\
\text { Pain }\end{array}$ & $\begin{array}{ll}\ldots & \ldots \\
\ldots & \ldots\end{array}$ & $\begin{array}{l}25 \\
40\end{array}$ & $\begin{array}{l}33 \\
17\end{array}$ & $\begin{array}{l}11 \\
11\end{array}$ & $\overline{1}$ \\
\hline
\end{tabular}

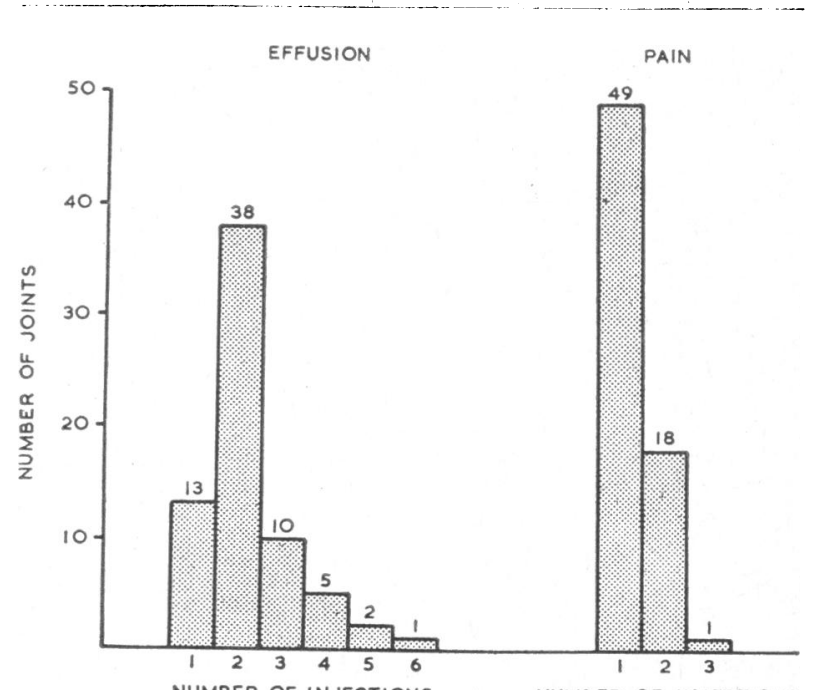

FIG. 1.-Number of injections required to produce complete relief of pain and resolution of effusion in 69 rheumatoid joints. (One joint was painless throughout.) 